\title{
Application of smart flap for race car wings
}

\section{Mohamad Hassan Djavareshkian* and Ali Esmaeli}

Mechanical Engineering Department, Faculty of Engineering,

Ferdowsi University of Mashhad, Mashhad, Iran

E-mail: javareshkian@um.ac.ir

E-mail: aliesmaeli30316@yahoo.com

*Corresponding author

\begin{abstract}
A pressure-based implicit procedure is due to solve Navier-Stokes equations. A non-orthogonal mesh with collocated finite volume formulation is used to simulate flow around the smart and conventional flaps of airfoil under the ground effect. Cantilever beam with uniformly varying load with roller support at the free end is considered for smart flaps. The boundedness criteria for this procedure are determined by a normalised variable diagram (NVD) scheme. The procedure incorporates the $k-\varepsilon$ eddy-viscosity turbulence model. The method is first validated against experimental data. Then, the SIMPLE algorithm is applied for turbulent aerodynamic flows around airfoil with smart and conventional flaps for different attack angle, flap angle and ground clearance where the results of two flaps are compared. It is found that the pressure coefficient distribution in a smart flap is smoother than a conventional one. The comparisons show that the quality of the solution is considerable.
\end{abstract}

Keywords: smart airfoil; ground effect; flap; aerodynamic coefficients; race car.

Reference to this paper should be made as follows: Djavareshkian, M.H. and Esmaeli, A. (2012) 'Application of smart flap for race car wings', Int. J. Aerodynamics, Vol. 2, No. 1, pp.66-92.

Biographical notes: Mohamad Hassan Djavareshkian received his MSc in Fluid Mechanic from Liverpool University, England, in 1993 and his PhD in Computational Fluid Dynamics and Aerodynamics from Imperial College of Science and Technology, England, in 1997. His major fields of study are computational fluid dynamics and aerodynamics. His has published more than 80 papers in international journal and presented at national and international scientific assemblies. Currently, he is working at the Mechanical Engineering Department of Ferdowsi University of Mashhad.

Ali Esmaeli is an MSc Aerodynamic Engineering Student from Ferdowsi University of Mashhad. He is currently doing his research about smart material and application of this material in the aerospace science and investigates optimisation algorithm. He has written eight international journals and nine international conference papers. 


\section{Introduction}

The total aerodynamic package of the race car is now emphasised more than ever. The use of aerodynamics to increase the cars grip is pioneered in Formula one in the late 1960s by Lotus, Ferrari and Brabham. Aerodynamics plays a vital role in determining speed and acceleration and thus performance. While drag reduction is an important part of the research, down force generation plays a greater role in lap time reduction. In another side, it can be said that the down force is necessary for high speed cornering. Ground effect aerodynamics of race cars is concerned with generating down force, principally via low pressure on the surfaces nearest to the ground. These phenomena happen when a wing is going near the surface. As the mass flow and height under the airfoil are decreased, pressure begins to build on the lower surface of the airfoil. Air cushion is created by the high pressure that builds up under the wing.

Airfoils or wings are used in the front and rear of the car in an effort to generate more down force. The front wing of a race car is an important piece to make safety at high speed. The front wing produces about $1 / 3$ of the car's down force, and it has been experienced more modifications than rear wing. The front wing assembly is the first part of the car to meet the air mass. The flow field here is better than other parts of the car, because the air here has been disturbed the least. The wing is designed to produce down force and guides the air as it moves toward the body and rear of the car. Flaps and winglets may also be used. In setting up the front wing assembly, engineers have to consider what happens to the airflow as it travels toward the back of the car.

Zerihan and Zhang (2001) have studied about flap wing in ground effect for racing car application and shown that the normal force of the wing is increased and sharper stall is created. Krajnovic and Davidson (2005) have simulated flow around a simplified car and proved that large Eddy simulations (LES) method is useful in such flows as the flow around bodies where the separations are defined by the geometry. Ying-chao and Li-min (2006) have investigated a numerical solution for shape cars when they oppositely meet side-by-side in the tunnel. It has been found that it is feasible to use computational fluid dynamics (CFD) to simulate the transient aerodynamic phenomenon and the aerodynamic coefficients of the cars sharply change like sinusoidal functions. The aerodynamic forces on the cars when they meet each other, they have significant effect on the car handling stability. There are many design parameters in designing multi-element race car wings. To choose the best parameter values for the wings of a Formula SAE car, CFD is combined with highly fractional factorial design of experiments that it has been investigated by Jasper and Rudell (2006). A general overview of the racing vehicle R\&D process is studied by Ueno et al. (2006). A CFD simulation and analysis for a $50 \%$ scaled car model is presented in sufficient detail, with an emphasis on addressing its aerodynamic aspects. In designing a two-element wing for a race car, consisting of a main element and a flap, one parameter to be chosen is the ratio of the flap chord length to the main element chord length. Goto and Sakurai (2006) have found the optimal flap chord length by using CFD simulations in 2D FX63-137 airfoil. Some important findings are that the flap chord length should be $40 \%$ to $70 \%$ of the main element chord length, that the maximum down force occurs at the flap angle of about $50^{\circ}$, and that the flap chord length and angle should be smaller as long as the desired down force is obtained in order to reduce the drag. Reddy and Gupta (2006) have carried out front wing in the race car. They have simulated by utilising CFD software and founded the optimum angle of attack for a F1 car. They have shown that optimum angle occurs at 
4 degrees. The down force is initially increased with the increase in angle of inclination, but it is declined beyond 4 degrees. Katz (2005) has done aerodynamic of race car and typical design tools such as wind tunnel testing, CFD and track testing and also their relevance to race car development are discussed. Mokhtar $(2005,2008)$ has studied low Reynolds's number flow around wings with and without ground effect. The mentioned study was extended to three-dimensional flow around a wing with ground effect (Mokhtar, 2008). Mokhtar and Lane (2009) have looked into a numerical study of a race car front wing. The focus of their study is to investigate the aerodynamics characteristics of a wing operating in a small ground clearance. A computational study in order to model the flow around an inverted airfoil in ground effect has been performed by Zerihan and Zhang (2000). Vu (2006) has applied wing tip vortices in inverted airfoils close to the ground for use in racing car.

The knowledge of the effects that the ground can have on airfoils dates back to the early 1920s. In recent years, there have been successful investigations on the aerodynamics of airfoil and wing. One of the more recent wind tunnel experiments have been done by Ahmed et al. (2003) and Ahmed and Sharma (2005). The effect of variation of angle of attack and ground clearance on aerodynamic characteristics of symmetrical airfoil by using a fixed and moving ground plane in a wind tunnel has been investigated by Ahmed et al. (2006). The investigation of unsteady varying of ground clearance has been performed by Takahisa et al. (2006). Jung et al. (2008) have simulated three-dimensional NACA6409 in ground proximity. Smith (2007) and Smith et al. (2008) have performed the computational analysis of airfoils in ground effect. The influence of endplate on aerodynamic characteristics for low-aspect-ratio wing in ground effect is performed by Park and Lee (2008). Moon et al. (2005) have examined three-dimensional wings in ground effect for aero-levitation electric vehicle. Numerical optimal design of a wing in-ground-effect craft has been done by Kim et al. (2009). Park et al. (2009) have presented the optimisation of airfoil under the ground effect. The effect of ground proximity on the aerodynamic performance and stability of a light unmanned aerial vehicle has been carried out by Boschetti et al. (2010). The shape optimisation using the multi-objective genetic algorithm and the analysis of the three-dimensional wings in ground effect have been offered by Lee et al. (2010).

Due to the potential benefits of employing adaptive airfoil, there has been an intensive attempt by researchers in developing a working model. With the advancement of materials, many researchers are now considering using smart materials to produce airfoil with variable camber capability. An analytical study has been conducted by NASA on the benefits of variable-camber capability (Bolonkin et al., 1999). Another advantage of adaptive airfoil is that it causes smaller vortex with less power. This is the result of Pern and Jacob (1999) research. They have used piezoelectric stimulus with a steel layer in airfoil. In 1997, Kudva et al. (1997) have discussed smart structure technologies and their benefits. In 2003, Forster et al. (2003) have designed a two-dimensional airfoil with a control surface in trailing edge that has a chord wise geometrical changes. In 2003, a joint project is carried out between US Aerospace Research Center (NASA) and Germany Aerospace Research Center (NGC) in the field of smart wing application (Florance et al., 2003). Recently, a multi-blade fan with smart material (memory alloy) that its intake can be varied by electrical stimulation has been suggested (Quackenbush et al., 2005). The other advantage of utilising smart material is in reducing vibration of helicopter blades (Anusonti-Inthra et al., 2005). The produced noise by airplane and helicopters can be reduced by smart material (Tiseo and Koopmann, 2006). In 2010, 
Barlas and van Kuik (2010) have introduced a new idea about using smart technology in wind turbine. Another way of applying smart material in airfoil is that flap ribs can be made by smart material such as piezoelectric or memory alloy. That is what is carried out in 2005 by Campanile and Anders (2005). Chinnasamy and Chen (2005) have investigated the aerodynamic coefficients. Matsuzaki and Torii (2006) have predicted flutter in smart wing. Smart material could be used as wing skins. These wings are called flexible wings. Majji et al. (2007) have examined a flexible three-dimensional wing in a research. Abdullah et al. (2009) have succeeded in making adaptive airfoils with using shape memory alloy (NiTi) and flexible skins. Wickramasinghe et al. (2009) have made a flight device with ribs by piezoelectric fibre. Abdullah et al. (2010) studied about an adaptive airfoil system using shape memory alloy (SMA) actuators. A wind tunnel test has been performed to investigate the change in lift to drag ratio of the wing when the actuator is switched on or off. The results have proved that the use of SMA actuators in the wing model is reliable. Also, a significant change in lift to drag ratio is detected when the wing is morphed.

Conventional wings have been used in the most of the researches for race cars. To improve aerodynamic coefficient performance, smart wing can be used in these cars. In this research, the smart flap is employed and simulated for an airfoil in ground clearance. In this simulation, the performance of airfoil with smart and conventional flaps for different length, flap angle and ground clearance are studied.

\section{Numerical solution setup and conditions}

\subsection{Simulation smart flap deflection}

In this study, smart flap deflection is designed with a cantilever beam so that the beam bending equation is the same smart flap chord deflection. Since flap shape is a triangle, the cantilever beams with uniformly varying load are considered in Figure 2. Different type of beams were analysed to find the bending equation of a flap (Chinnasamy and Chen, 2005). For analysis of flap, usually is used a cantilever beam with uniformly varying load with roller support at the free end. The same profile is also used by Chinnasamy and Chen (2005). The above-mentioned profile is given, below:

$$
Y=\frac{w_{0}\left(-X^{5}+2 B^{2} X^{3}-B^{4} X\right)}{120 E \overline{I B}}
$$

Since the parametric equation is only needed, equation (1) is substituted by equation (2).

$$
\begin{aligned}
& Y_{\text {Midline }}=K\left(-X^{5}-a X^{3}+X\right) \\
& Y_{\text {Upper }}=Y_{u}+K_{u}\left(-X^{5}-a X^{3}+X\right) \\
& Y_{\text {Lower }}=Y_{L}+K_{L}\left(-X^{5}-a X^{3}+X\right) \\
& a=\frac{1-B^{4}}{B^{2}}
\end{aligned}
$$


Smart flap geometry profile has not fixed in different angle of flaps (AOFs). $K$ in equation (2) is a parameter so that it is changed in different AOFs.

Figure 1 Smart and convectional flap

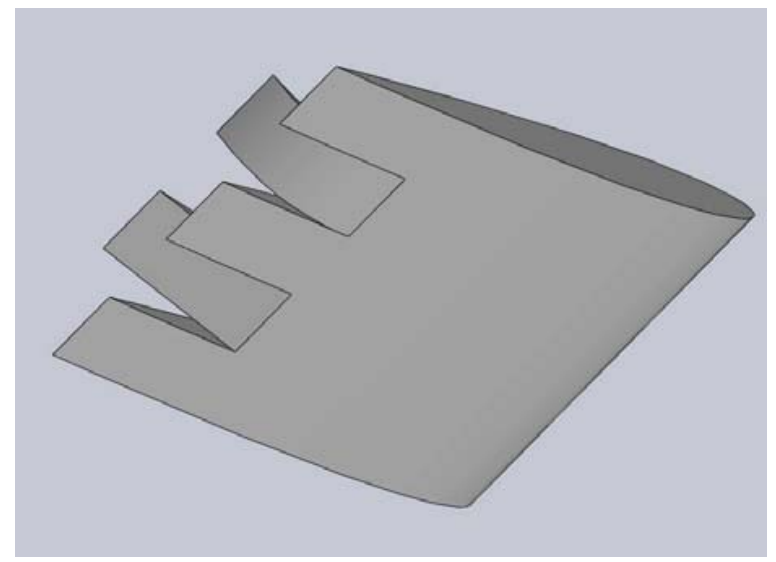

Figure 2 Cantilever beam model

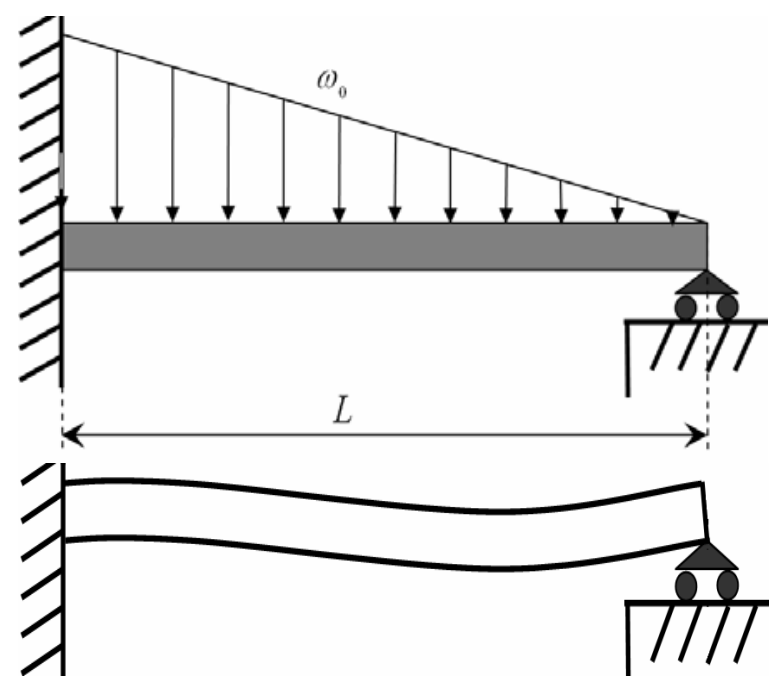

The bending equation can be used for midline. For upper and lower flap surface, the configuration was manipulated by making minor modifications. The coefficients of equation (2) are determined by iterative process. Each profile is visualised using FORTRAN, and the value of the coefficient is either increased or decreased until the desired profile is obtained. A parametric smart airfoil is designed and CFD simulation is done over them. 


\subsection{Governing equation for fluid}

The basic equations which describe conservation of mass, momentum and scalar quantities can be expressed in the following vector form. They are independent in the used coordinate system.

$$
\begin{aligned}
& \frac{\partial \rho}{\partial t}+\operatorname{div}(\rho \overrightarrow{\mathbf{V}})=S_{m} \\
& \frac{\partial(\rho \overrightarrow{\mathbf{V}})}{\partial t}+\operatorname{div}(\rho \overrightarrow{\mathbf{V}} \otimes \overrightarrow{\mathbf{V}}-\overrightarrow{\mathbf{T}})=\overrightarrow{\mathbf{S}}_{\mathbf{v}} \\
& \frac{\partial(\rho \phi)}{\partial t}+\operatorname{div}(\rho \overrightarrow{\mathbf{V}} \phi-\overrightarrow{\mathbf{q}})=\overrightarrow{\mathbf{S}}_{\boldsymbol{\Phi}}
\end{aligned}
$$

where $\rho, \overrightarrow{\mathbf{V}}$ and $\phi$ are density, velocity vector and scalar quantity respectively, $\overrightarrow{\mathbf{T}}$ is the stress tensor and $\overrightarrow{\mathbf{q}}$ is the scalar flux vector. The latter two are usually expressed in terms of basic dependent variables. The stress tensor for a Newtonian fluid is:

$$
\vec{T}=-P \vec{I}+2 \mu \vec{D}
$$

and the Fourier-type law usually gives the scalar flux vector:

$$
\overrightarrow{\mathbf{q}}=\Gamma_{\phi} \operatorname{grad} \Phi
$$

For the purpose of illustration equation (5), it may be expressed in 2D Cartesian coordinates as:

$$
\overbrace{\frac{\partial(\rho \varphi)}{\partial t}}^{\text {transient term }}+\overbrace{\frac{\partial(\rho u \varphi)}{\partial x}+\frac{\partial(\rho v \varphi)}{\partial y}}^{\text {convection term }}-\overbrace{\frac{\partial}{\partial x}\left(\Gamma_{\varphi} \frac{\partial \varphi}{\partial x}\right)-\frac{\partial}{\partial y}\left(\Gamma_{\varphi} \frac{\partial \varphi}{\partial y}\right)}^{\text {diffusion term }}=\overbrace{S_{\varphi}}^{\text {source }}
$$

Turbulence is accounted for by adopting the $k-\varepsilon$ turbulence model. The governing equations for these quantities are:

$$
\begin{aligned}
& \frac{\partial}{\partial t}(\rho k)+\frac{\partial}{\partial x_{j}}\left(\rho u_{j} k-\Gamma_{k} \frac{\partial k}{\partial x_{j}}\right)=G-\rho \varepsilon \\
& \frac{\partial}{\partial t}(\rho \varepsilon)+\frac{\partial}{\partial x_{j}}\left(\rho u_{j} \varepsilon-\Gamma_{\varepsilon} \frac{\partial \varepsilon}{\partial x_{j}}\right)=C_{1} \frac{\varepsilon}{k} G-C_{2} \rho \frac{\varepsilon^{2}}{k}
\end{aligned}
$$

The turbulent viscosity and diffusivity coefficients are defined as:

$$
\begin{gathered}
\mu_{t}=C_{\mu} \rho \frac{k^{2}}{\varepsilon} \\
\Gamma_{\phi}^{t}=\left(\frac{\mu_{t}}{\sigma_{\phi}^{t}}\right)
\end{gathered}
$$


and the generation term $G$ in equations (6) and (7) is defined as:

$$
G=\mu_{t}\left[\left(\frac{\partial u_{i}}{\partial x_{j}}+\frac{\partial u_{j}}{\partial x_{i}}\right) \frac{\partial u_{i}}{\partial x_{j}}\right]
$$

\subsection{Finite-volume discretisation}

The discretisation of the above differential equations is carried out by using a finite-volume approach. First, the solution domain is divided into a finite number of discrete volumes or cells, where all variables are stored at their geometric centres (see e.g., Figure 3). The equations are then integrated over all the control volumes by utilising the Gaussian theorem. The discrete expressions are presented to referee to only one face of the control volume, namely, $e$, for the sake of brevity.

Figure 3 Finite volume and storage (see online version for colours)

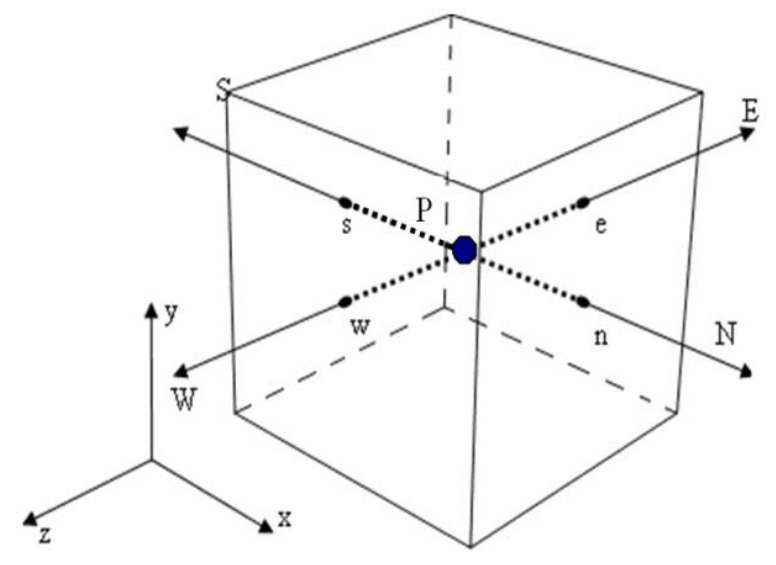

For any variable $\phi$ (which may also stand for the velocity components), the result of the integration yields:

$$
\frac{\delta v}{\delta t}\left[(\rho \varphi)_{p}^{n+1}-(\rho \varphi)_{p}^{n}\right]+I_{e}-I_{w}+I_{n}-I_{s}=S_{\varphi} \delta v
$$

where $I$ 's are the combined cell-face convection $I^{c}$ and diffusion $I^{D}$ fluxes. The diffusion flux is approximated by central differences and can be written for cell-face (e) of the control volume in Figure 3 as:

$$
I_{e}^{D}=D_{e}\left(\phi_{P}-\phi_{E}\right)-S_{e}^{\phi}
$$

where $S_{e}^{\phi}$ stands for cross derivative arising from mesh non-orthogonality. The discretisation of the convective flux requires special attention and it causes to develop the various schemes. A representation of the convective flux for cell-face (e) is:

$$
I_{e}^{c}=(\rho . V . A)_{e} \varphi_{e}=F_{e} \varphi_{e}
$$


The value of $\phi_{e}$ is not known and it should be estimated from the values at neighbouring grid points by interpolation. The expression for the $\varphi_{e}$ is determined by the SBIC scheme (Djavareshkian, 2001) that is based on the normalised variable diagram (NVD) technique using interpolation from the nodes $\mathrm{E}, \mathrm{P}$ and $\mathrm{W}$. The expression can be written as:

$$
\phi_{e}=\phi_{W}+\left(\phi_{E}-\phi_{W}\right) \cdot \tilde{\phi}_{e}
$$

The functional relationship utilised in SBIC scheme for $\tilde{\phi}_{e}$ is illustrated in Figure 3 and is given as:

$$
\begin{aligned}
& \tilde{\varphi}_{e}=\tilde{\varphi}_{p}, \quad I F \tilde{\varphi}_{P} \notin[0,1] \\
& \tilde{\varphi}_{e}=-\frac{\tilde{x}_{p}-\tilde{x}_{e}}{\kappa\left(\tilde{x}_{p}-1\right)} \tilde{\varphi}_{p}^{2}+\left(1+\frac{\tilde{x}_{p}-\tilde{x}_{e}}{\kappa\left(\tilde{x}_{p}-1\right)}\right) \tilde{\varphi}_{p}, \quad I F \tilde{\varphi}_{P} \in[0, \kappa] \\
& \tilde{\varphi}_{e}=\frac{\tilde{x}_{p}-\tilde{x}_{e}}{\tilde{x}_{p}-1}+\frac{\tilde{x}_{p}-1}{\tilde{x}_{p}-1} \tilde{\varphi}_{p}, \quad I F \tilde{\varphi}_{P} \in[\kappa, 1]
\end{aligned}
$$

where

$$
\begin{aligned}
& \tilde{\phi}_{p}=\frac{\phi_{p}-\phi_{W}}{\phi_{E}-\phi_{W}}, \quad \tilde{\phi}_{e}=\frac{\phi_{e}-\phi_{W}}{\phi_{E}-\phi_{W}} \\
& \tilde{x}_{p}=\frac{x_{p}-x_{W}}{x_{E}-x_{W}}, \quad \tilde{x}_{e}=\frac{x_{e}-x_{W}}{x_{E}-x_{W}}
\end{aligned}
$$

The limits on the selection of $\kappa$ could be determined in the following way. Obviously, the lower limit is $\kappa=0$, which would represent switching between upwind and central differencing. It is not favourable, because it is essential to avoid the abrupt switching between the schemes in order to achieve the converged solution. The value of $\kappa$ should be kept as low as possible in order to attain the maximum resolution of the scheme. The final form of the discretised equation from each approximation is given as:

$$
A_{P} \cdot \phi_{P}=\sum_{m=E, W, N, S} A_{m} \cdot \phi_{m}+S_{\phi}^{\prime}+S_{d c}
$$

where $A$ 's are the convection-diffusion coefficients. The term $s_{\phi}^{\prime}$ in equation (20) contains quantities arising from non-orthogonality, numerical dissipation terms and external sources, and $(\rho \delta v / \delta t) \phi_{P}$ of the old time-step/iteration level (for time dependent equation). For the momentum equations, it is easy to separate out the pressure-gradient source from the convected momentum fluxes. $S_{d c}$ is the contribution due to the adapted deferred correction procedure.

\subsection{Solution algorithm}

Most contemporary pressure-based methods employ a sequential iteration technique in which the different conservation equations are solved one after another. The common approach taken in enforcing continuity is by combining the equation for continuity with those of momentum to derive an equation for pressure or pressure-correction. The present 
work applies the SIMPLE technique in which the implicitly discretised equations are solved at each time-step by a sequence of predictor and corrector steps. This scheme is especially efficient for unsteady flows, as it does not involve expensive iteration. For steady flows, time marching is effected until the steady state is reached.

\section{Results and discussion}

\subsection{Grid strategy}

The grid structure that is used in CFD simulation is created by a structured mesh employed, because of its simplicity and applicability to the current flow configuration (i.e., with a near-by ground). Schematic shape of these two-dimensional structured grids is shown in Figure 4. According to Figure 5, the dimension of domain has been obtained after doing several various lengths for $b, f, u$ and independent lengths have been chosen. The grid sizing is determined after grid independence that is found by doing several different trials. For example, the effect of grid size is shown in Figure 6 which shows surface pressure coefficient distribution. For other cases, the above process is used for grid and domain independences.

Figure 4 Grid topology and $\mathrm{H}$ grid (see online version for colours)

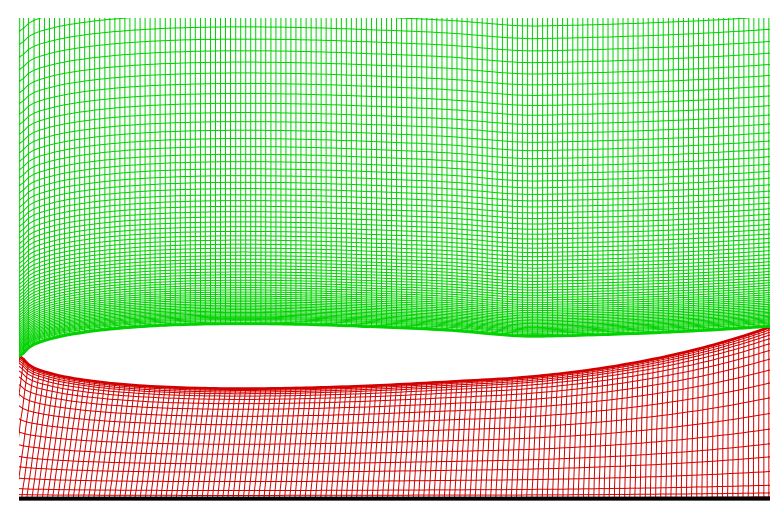

Figure 5 Dimension of domain (see online version for colours)

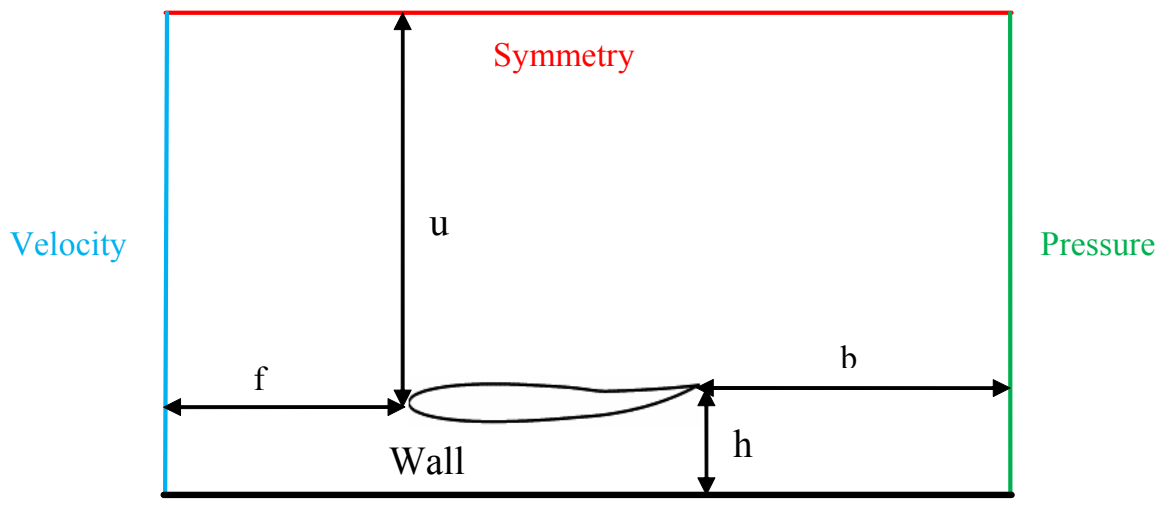


Figure 6 Effect of grid sizing on pressure distribution on the surface of the airfoil for an angle of attack $10^{\circ}$ and $\mathrm{h} / \mathrm{c}=0.2$ (see online version for colours)

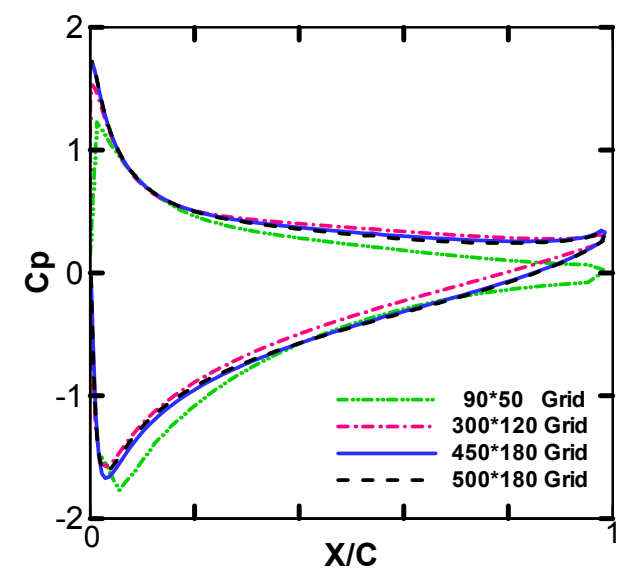

Figure $7 \quad \mathrm{Y}+$ distribution on the upper surface of airfoil (see online version for colours)

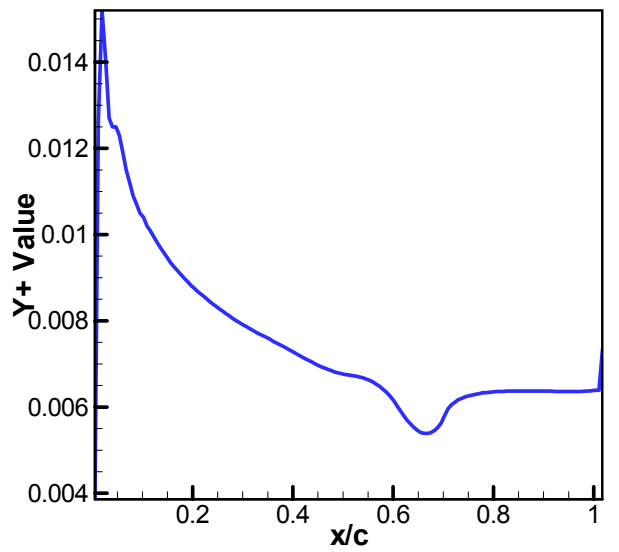

Figure 8 Y+ distribution on the lower surface of airfoil (see online version for colours)

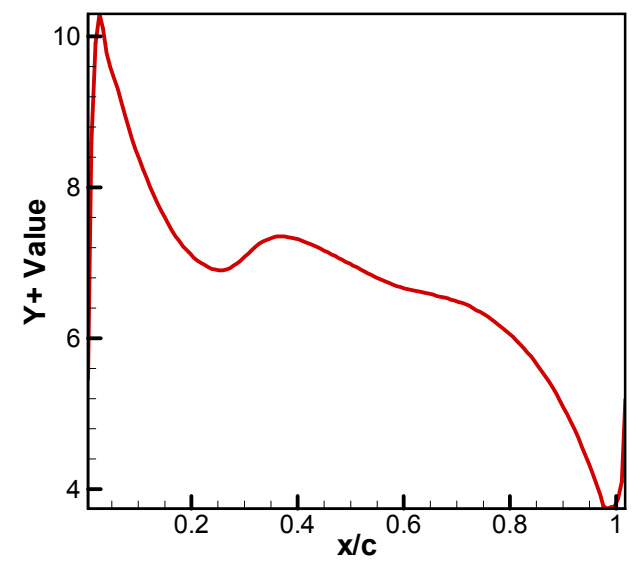


Figure 7 and Figure 8 show $\mathrm{Y}+$ value on the upper and lower surface of the airfoil, respectively. The figures indicate that the centre of cells is located in the sub-layer.

In actual problem, the ground is moving with respect to WIG craft, but in usual experimental tests, ground is fixed. Figures 9 and 10 represent the effect of moving and fixed ground. The comparison of figures shows that the effect of moving ground in the small ground clearance $(\mathrm{h} / \mathrm{c}=0.05)$ has little effect on simulation and in high ground clearance $(\mathrm{h} / \mathrm{c}=0.8)$ there is no difference between moving and fixed ground. Altogether, it is not important factor in simulation.

Figure 9 Effect of fixed and moving ground on pressure distribution on the surface of the airfoil for an $\mathrm{AOA}=10^{\circ}$ and $\mathrm{h} / \mathrm{c}=0.8$

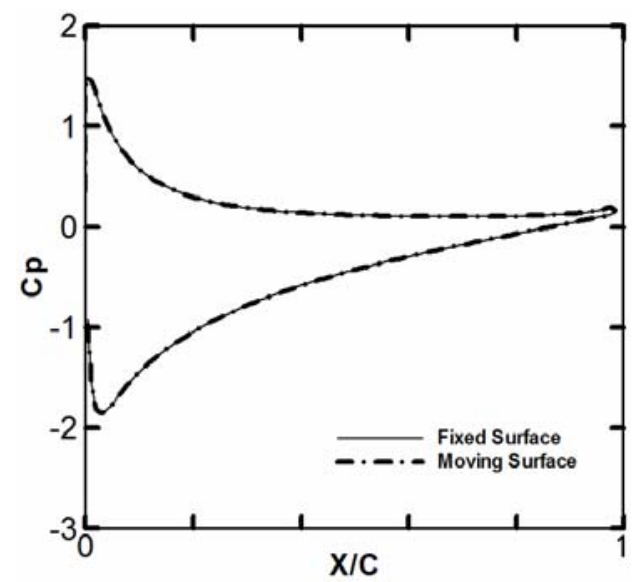

Figure 10 Effect of fixed and moving ground on pressure distribution the surface of the airfoil for an $\mathrm{AOA}=10^{\circ}$ and $\mathrm{h} / \mathrm{c}=0.05$

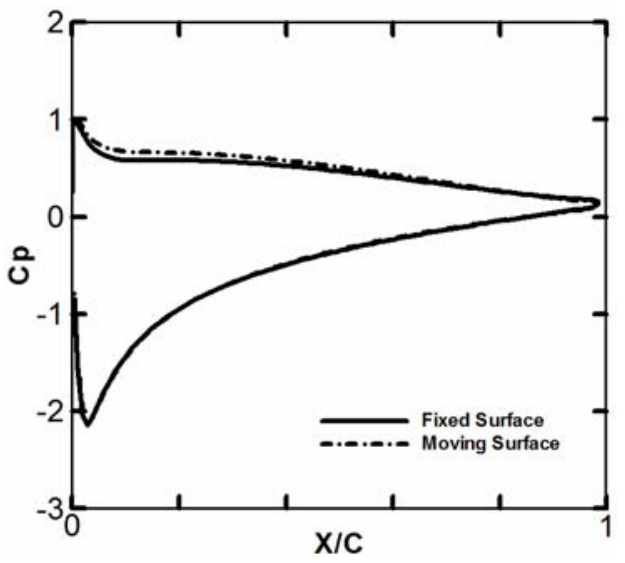




\subsection{Boundary conditions}

Figure 5 shows the boundary condition. At the inlet, velocity has been prescribed. At the outlet, the pressure is fixed. Slip boundary conditions are used on upper walls of the domain and wall boundary conditions are utilised for airfoil surface and ground surface.

\subsection{Results}

The results are presented and discussed in this section. Table 1 shows the setting for numerical simulation. At first, the simulation of flow around the airfoil NACA0015 has been performed. Then, the effects of flow around airfoil NACA0009 with flap in smart and conventional conditions, AOF and ground clearance have been investigated. The simulation is two-dimensional. Pressure coefficient distribution, velocity profile, wake flow, lift and drag coefficients of the airfoil have been analysed. The Reynolds number for this study is $2.4 \times 10^{5}$. This number indicates that the airflow has full turbulent regions. Also $k-\varepsilon$ model is used. The model is simple and has a good stability and an easy convergence. The angle of attack for all of the cases is zero and maximum of the $\mathrm{AOF}$ is $7.5^{\circ}$ and there is not strong separation. Also, flow filed is not swirl and complicated. As a result of this, the $k-\varepsilon$ model has been chosen in the simulation. The model is cheap and it is a public turbulent model. The comparison of experimental and numerical data shows that the $k-\varepsilon$ model is suitable, too.

Table 1 Settings for numerical simulation

\begin{tabular}{lc}
\hline Flow & Turbulent \\
\hline Precision & Two-dimension double precision \\
Scheme & Normalise variable diagram \\
Solver & SIMPLE \\
Turbulent model & $k-\varepsilon$ \\
\hline
\end{tabular}

Figure 11 Pressure coefficient distribution on the surface of the airfoil NACA 0015 for an $\mathrm{AOA}=7.5^{\circ}$ and $\mathrm{h} / \mathrm{c}=0.8$ (see online version for colours)

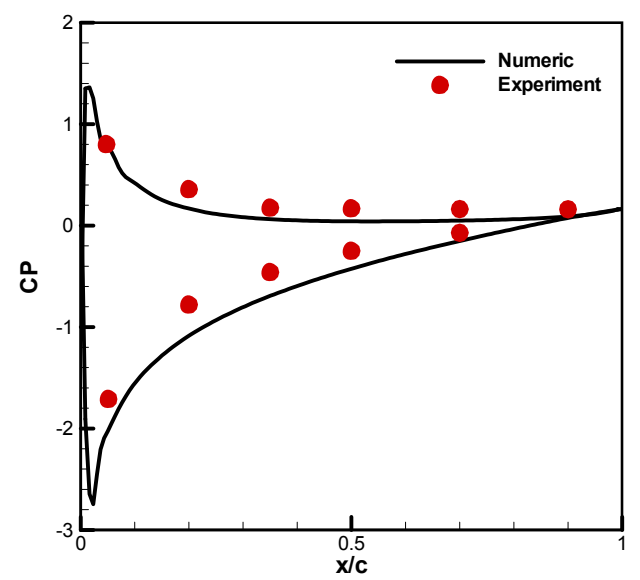


In the numerical simulation, it is important to achieve a validation. Then, it is necessary to compare numerical result with experimental data. The numerical and experimental pressure coefficient distributions on the surface of the airfoil are compared in angle of attack $7.5^{\circ}$ and ground clearance $\mathrm{h} / \mathrm{c}=0.8$ in Figure 11. It can be seen that there is a good agreement between present numerical and experimental data (Ahmed and Sharma, 2005). Table 2 also shows lift coefficients and error percent. The numerical results are in good agreement with experiment data. Table 2 illustrates that the difference between experimental and numerical data is low and the maximum of error is $13 \%$.

Table 2 Comparison of lift coefficients for airfoil NACA 0015 for AOA $=7.5^{\circ}$

\begin{tabular}{lccc}
\hline$h / c$ & Experiment & Numeric & Error\% \\
\hline 0.1 & 0.983 & 0.855 & 13 \\
0.5 & 0.845 & 0.756 & 10 \\
0.8 & 0.779 & 0.735 & 6 \\
\hline
\end{tabular}

The airfoil NACA0009 is selected in this study. The simulation method for this test case is the same as pervious one. Airflow treatment and effect of the flap in smart and conventional conditions in ground proximity are investigated. When the ground clearance is decreased, airfoil performance is changed. Figure 12 and Figure 13, respectively is illustrated the pressure coefficient distribution on the surface of smart and conventional airfoils for $\mathrm{AOF}=+50$ and different ground clearance. When the flap is deflected to upward, pressure side is related to the upper surface of airfoil and suction side is related to the lower surface of airfoil. The comparison of Figure 12 and Figure 13 manifests the advantage of smart flap. The zones marked with circle are showed in Figure 12 and Figure 13. This zone is the junction region of flap to the airfoil. These figures indicate the sudden change in the upper surface pressure coefficient distribution in conventional flap, while it is smooth for smart case. This sudden change is due to the sharp change of airfoil surface in junction zone for conventional airfoil. As the result of this, absolute of down force coefficient in the conventional flap is less than smart flap, because pressure distribution on the upper and lower airfoil surface for smart flap is smoother than conventional flap and the difference of pressure in the smart cases is more than conventional ones. Table 3 shows down force (lift) and drag coefficients and L/D for smart and conventional flaps. The comparisons prove that the absolute of down force coefficient of smart flap is more than conventional flap for all different ground clearance and drag coefficients have reverse treatment. Also, the L/D ratio of smart flap is higher than conventional one. The drag coefficient of smart flap is less than conventional one, because flow around the smart cases are not separated, but in conventional airfoil, a sudden change of airfoil surface is present in junction zone, so that this phenomenon causes separation. As the result of this, the drag coefficient of conventional flap is more than smart one.

As Figure 12 and Figure 13 show, pressure is reduced by decreasing ground clearance in the pressure side. This behaviour happens in both smart and conventional flaps. Pressure coefficient in the pressure side and suction side are decreased by the reduction of ground clearance, but pressure coefficient reduction in the suction side is more. Hence, the absolute of down force coefficient is more at close ground clearance. 
Figure 12 Pressure coefficient distribution on the surface of the smart airfoil for $\mathrm{AOF}=+5^{\circ}$ (see online version for colours)

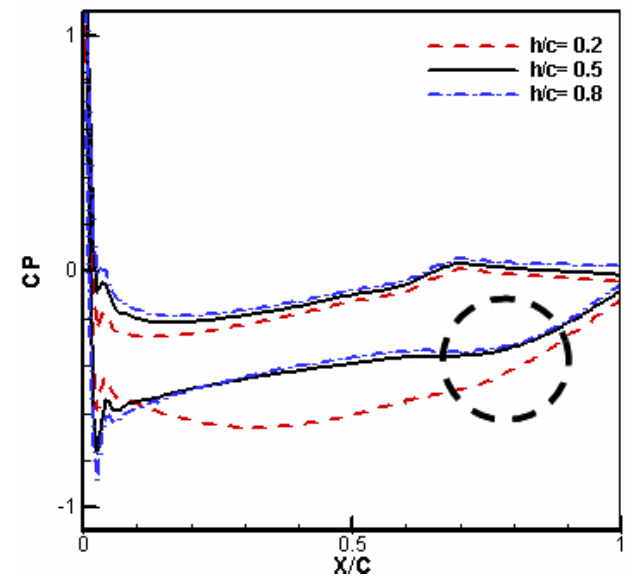

Figure 13 Pressure coefficient distribution on the surface of the conventional airfoil for $\mathrm{AOF}=+5^{\circ}$ (see online version for colours)

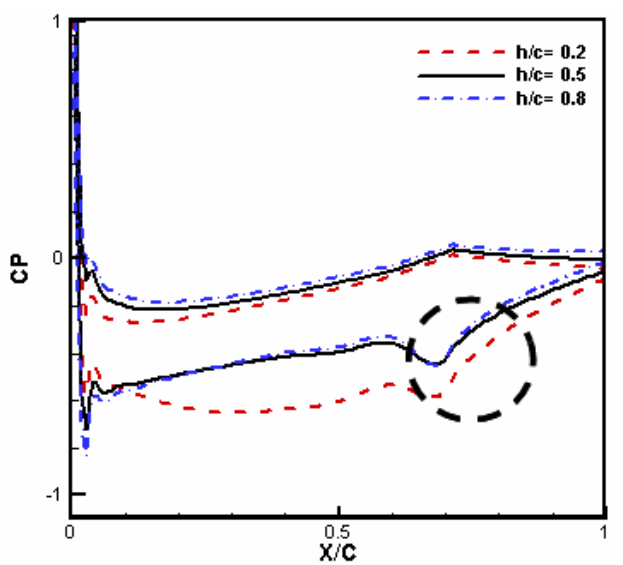

Table 3 Down force (lift), drag coefficients and lift-drag ratio for smart and conventional airfoils for $\mathrm{AOF}=+5^{\circ}$

\begin{tabular}{cccccccc}
\hline \multirow{2}{*}{$h / c$} & \multicolumn{3}{c}{ Smart flap } & & \multicolumn{3}{c}{ Convectional flap } \\
\cline { 2 - 3 } \cline { 6 - 8 } & $C L$ & $C D$ & $L / D$ & & $C L$ & $C D$ & $L / D$ \\
\hline 0.2 & -0.385 & 0.0382 & 10.1 & & -0.368 & 0.0386 & 9.53 \\
0.5 & -0.309 & 0.0295 & 10.5 & & -0.288 & 0.0305 & 9.44 \\
0.8 & -0.337 & 0.0270 & 12.5 & & -0.308 & 0.0276 & 11.2 \\
\hline
\end{tabular}

Table 3 shows lift and drag coefficients for the different $\mathrm{h} / \mathrm{c}$. Drag coefficient is increased by the reduction ground clearance and this coefficient for conventional flaps is more than the smart mode for all the $\mathrm{h} / \mathrm{c}$ and AOF. The down force (lift) coefficient is increased by ground clearance, initially, then this coefficient is decreased by increasing ground clearance. When flap deflection is positive, the passing flow between the lower surface of 
airfoil and ground surface is like the passing flow in a nozzle. Nozzle characteristics have revealed that velocity is increased and pressure is reduced in the convergent part, so velocity is reached to maximum in the gorge and pressure is increased and velocity is decreased in the divergent part. When the ground clearance is reduced, the cross-section ratio is greater and flow expansion is more on the lower surface of airfoil. As a result of this, velocity on the lower surface of airfoil is increased. This increase of velocity in the lower surface with ground clearance from $\mathrm{h} / \mathrm{c}=0.8$ to $\mathrm{h} / \mathrm{c}=0.5$ increase lift coefficient. When the ground clearance is decreased from $\mathrm{h} / \mathrm{c}=0.5$ to $\mathrm{h} / \mathrm{c}=0.2$, boundary layer has an important role. The velocity in lower surface and lift coefficient are decreased. The phenomenon can be seen in Figures 14, 15 and 16. These figures show counters of the pressure coefficient around the airfoil with smart flap for different ground clearance.

Figure 14 Contours of pressure coefficient distribution around the smart airfoil with positive flap deflection for an $\mathrm{AOF}+2.5^{\circ}$ and $\mathrm{h} / \mathrm{c}=0.2$ (see online version for colours)

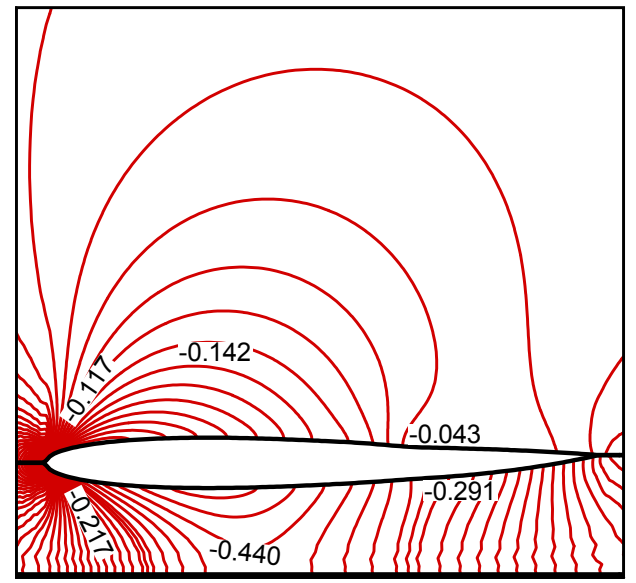

Figure 15 Contours of pressure coefficient distribution around the smart airfoil with positive flap deflection for an $\mathrm{AOF}=+2.5^{\circ}$ and $\mathrm{h} / \mathrm{c}=0.5$ (see online version for colours)

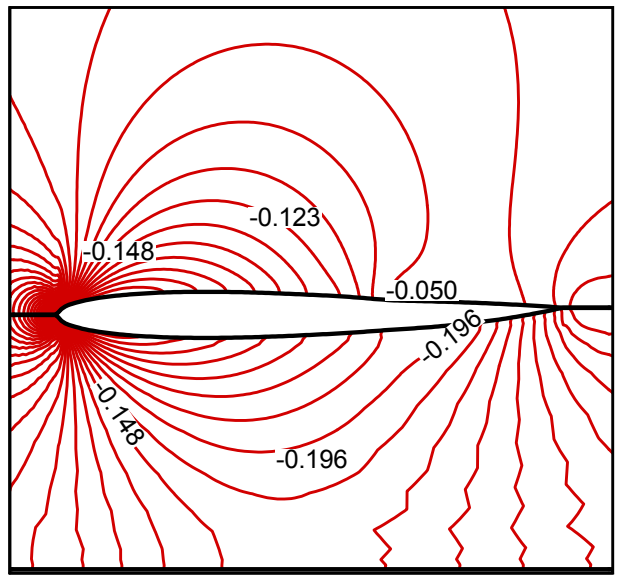


Figure 16 Contours of pressure coefficient distribution around the smart airfoil with positive flap deflection for an $\mathrm{AOF}=+2.5^{\circ}$ and $\mathrm{h} / \mathrm{c}=0.8$ (see online version for colours)

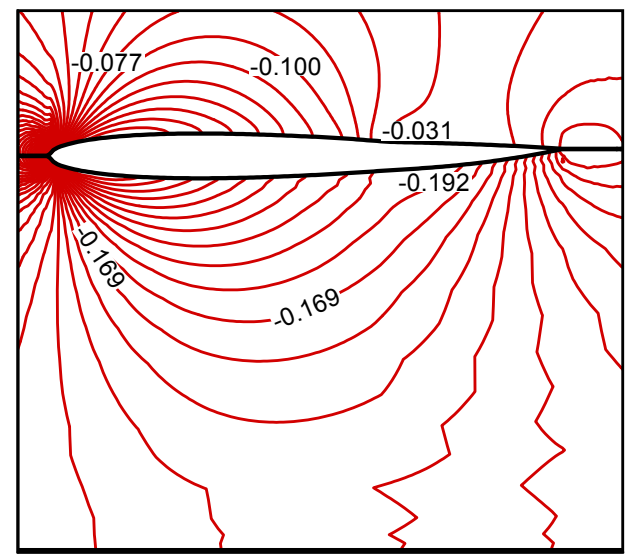

Figure 17 and Figure 18 illustrate pressure coefficient contours around the smart airfoil for $\mathrm{h} / \mathrm{c}=0.2, \mathrm{~h} / \mathrm{c}=0.8$. These results prove that the pressure is less at close ground clearance. The reduction of pressure is affected on the velocity profile, so that Figure 19 shows velocity profiles at the upper surface of smart airfoil. These figures manifest that velocity on the surface is increased by reduction ground clearance. Figure 20 shows velocity profiles in the lower surface of smart airfoil. The figures prove that velocity is increased by ground clearance reduction. The shear stress on the ground surface is increased by ground clearance reduction, too. However, velocity is increased and pressure is decreased on the upper and lower surface of airfoil with ground clearance reduction, but velocity in the lower surface of airfoil is more increased. Therefore, down force is increased by ground clearance decreasing. The $\mathrm{h} / \mathrm{c}$ distance influences on the wake behind the airfoil. When ground clearance is reduced, velocity difference between upper and lower surface of airfoil is more. Thus, the wake is stronger with reducing the gap (Figure 21). For this reason, drag is increased by ground clearance reduction.

Figure 17 Contours of pressure coefficient distribution on the surface of the smart airfoil for an $\mathrm{AOF}=+5^{\circ}$ and $\mathrm{h} / \mathrm{c}=0.2$ (see online version for colours)

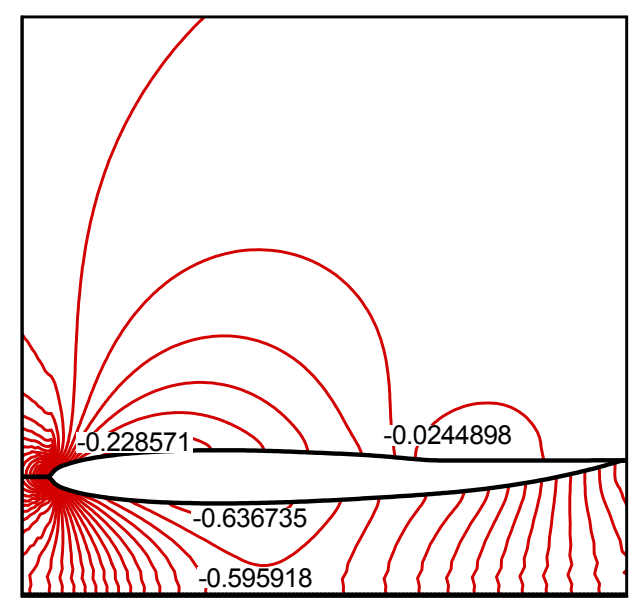


Figure 18 Contours of pressure coefficient distribution on the surface of the smart airfoil for an $\mathrm{AOF}=+5^{\circ}$ and $\mathrm{h} / \mathrm{c}=0.8$ (see online version for colours)

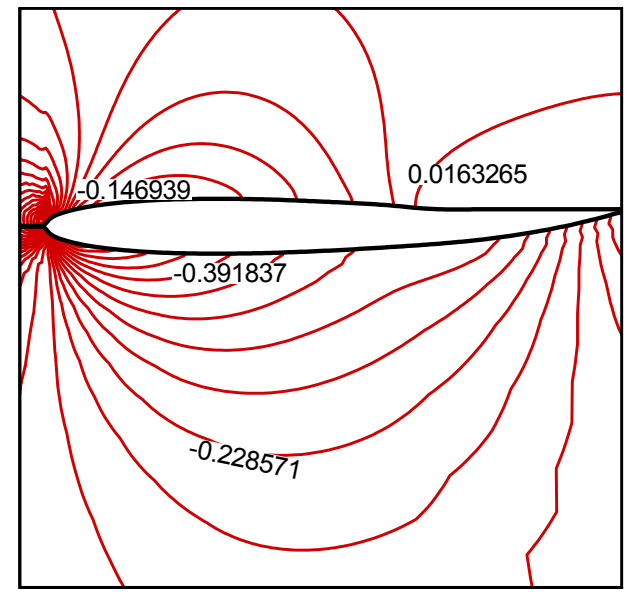

Figure 19 Velocity profile in upper surface of smart airfoil at AOF $=+5^{\circ}$, (a) $\mathrm{x} / \mathrm{c}=0.2$

(b) $\mathrm{x} / \mathrm{c}=0.85$ (see online version for colours)

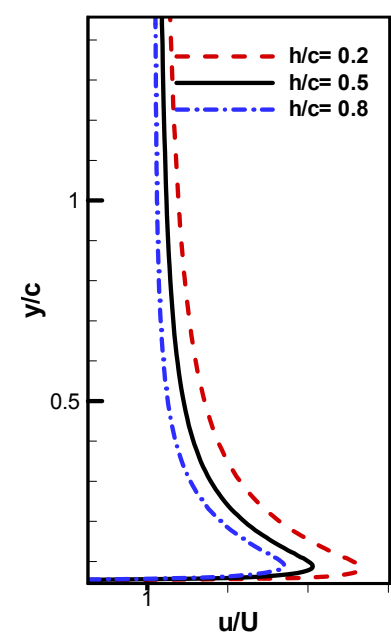

(a)

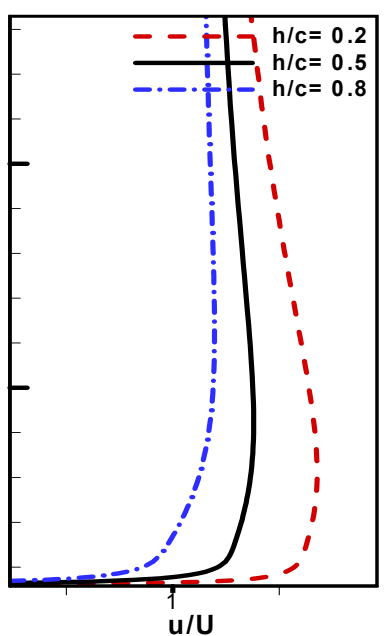

(b)

In Figure 22 and Figure 23, the effect of AOF for smart and conventional flaps at $\mathrm{h} / \mathrm{c}=0.8$ has been investigated. If the flap angle is increased, pressure will be increased on the upper surface of airfoil and it will be decreased in the lower surface of airfoil. The pressure coefficient distribution on the lower surface of the conventional airfoil has the sudden change. The zone marked with circle is showed in Figures 22 and 23. This zone is the junction region of flap to the airfoil. These figures indicate the sudden change in the upper surface pressure coefficient distribution in conventional flap, while it is smooth for smart case. This sudden change is due to the sharp change of airfoil surface in junction zone for conventional airfoil. As the result of this, absolute of down force coefficient in the conventional flap is less than smart one, because pressure distribution on the upper 
and lower airfoil surface for smart flap is smoother than conventional flap and the difference of pressure in the smart cases is more than conventional ones. The pressure coefficient contour around the smart and conventional airfoils has respectively been illustrated in Figure 24 and Figure 25. These results indicate that the pressure changes in conventional mode are more than the smart mode in low surface of airfoil.

Figure 20 Velocity profile in lower surface of smart airfoil at $\mathrm{AOF}=+5^{\circ}$, (a) $\mathrm{x} / \mathrm{c}=0.2$ (b) $\mathrm{x} / \mathrm{c}=0.85$ (see online version for colours)

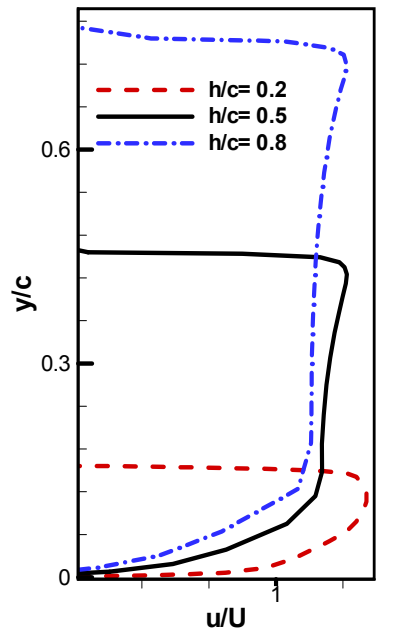

(a)

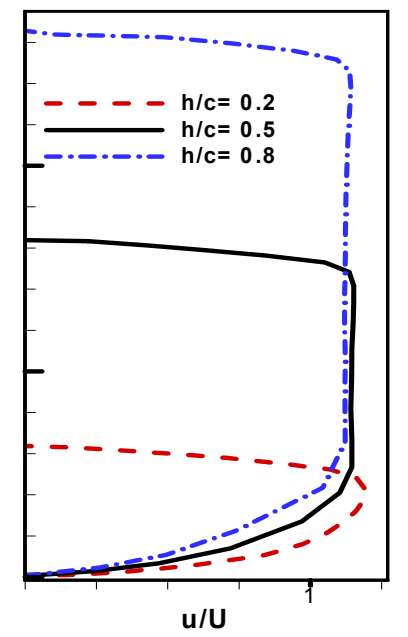

(b)

Figure 21 Velocity profile in behind the smart airfoil at $\mathrm{AOF}=+5^{\circ}$, (a) $\mathrm{x} / \mathrm{c}=1.08$ (b) $\mathrm{x} / \mathrm{c}=2$ (see online version for colours)

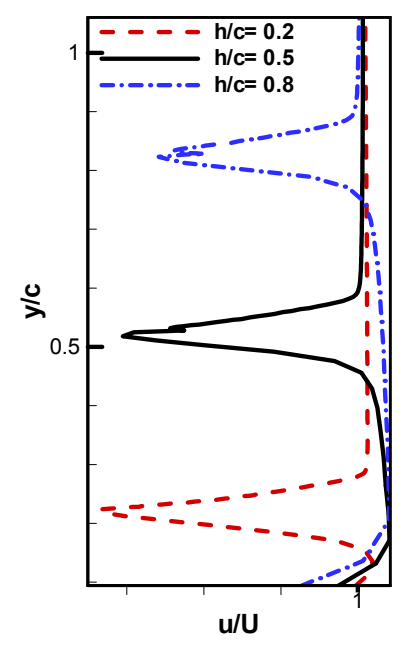

(a)

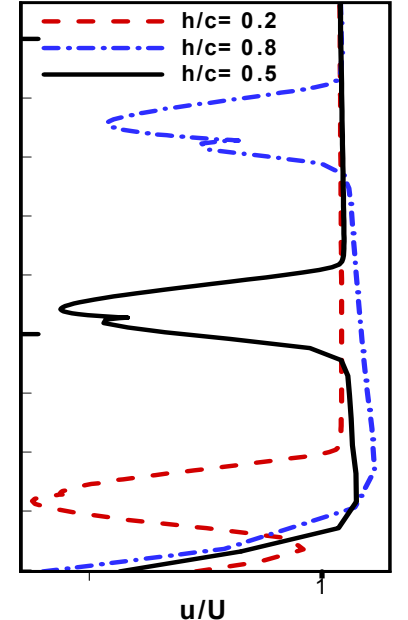

(b) 
Figure 22 Pressure coefficient distribution on the surface of the smart airfoil for $\mathrm{h} / \mathrm{c}=0.8$ (see online version for colours)

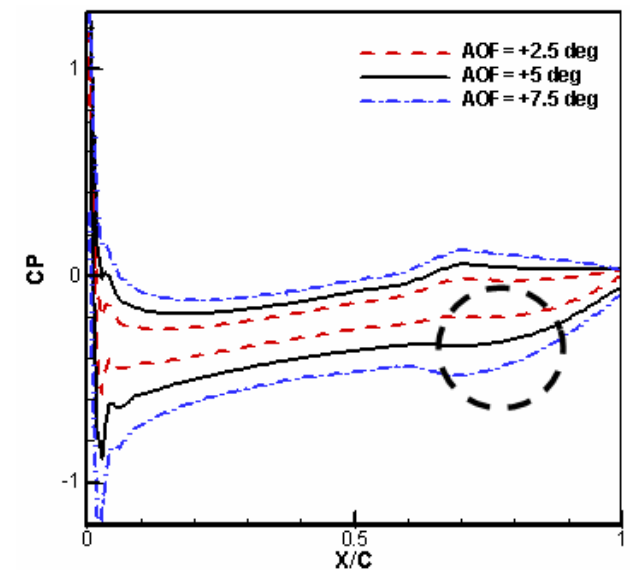

Figure 23 Pressure coefficient distribution on the surface of the conventional airfoil for $\mathrm{h} / \mathrm{c}=0.8$ (see online version for colours)

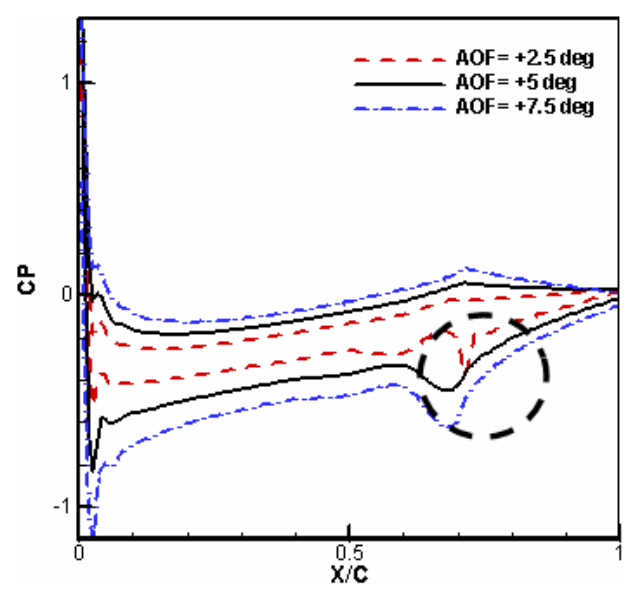

Table 4 demonstrates down force, drag coefficients and L/D for smart and conventional airfoils for $\mathrm{h} / \mathrm{c}=0.8$. Comparisons prove that down force coefficient of a smart flap is more than a conventional flap per all of AOF. Down force and drag coefficients are increased slightly with AOF for two airfoils. When the angle of attack is more, pressure in the pressure side is increased and pressure in the suction side is decreased. Then down force coefficient is increased. In the velocity profile can be seen good velocity change on the airfoil surface. 
Figure 24 Contours of pressure coefficient distribution around the conventional airfoil for an $\mathrm{AOF}=+2.5^{\circ}$ and $\mathrm{h} / \mathrm{c}=0.2$ (see online version for colours)

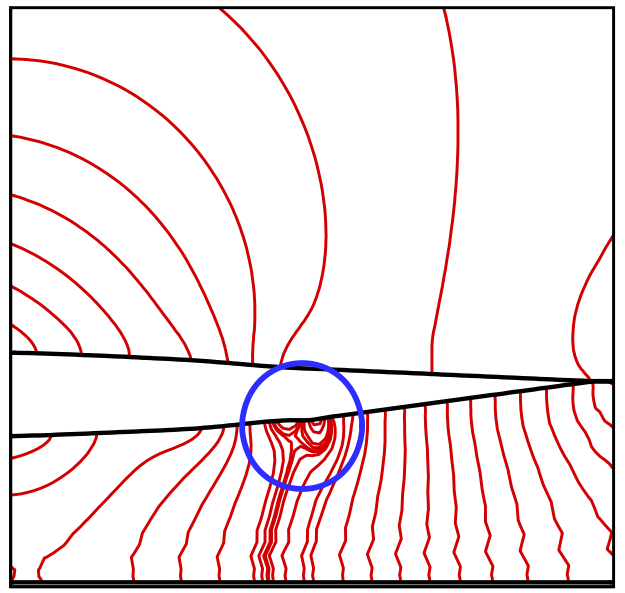

Figure 25 Contours of pressure coefficient distribution around the smart airfoil for an $\mathrm{AOF}=+2.5^{\circ}$ and $\mathrm{h} / \mathrm{c}=0.2$ (see online version for colours)

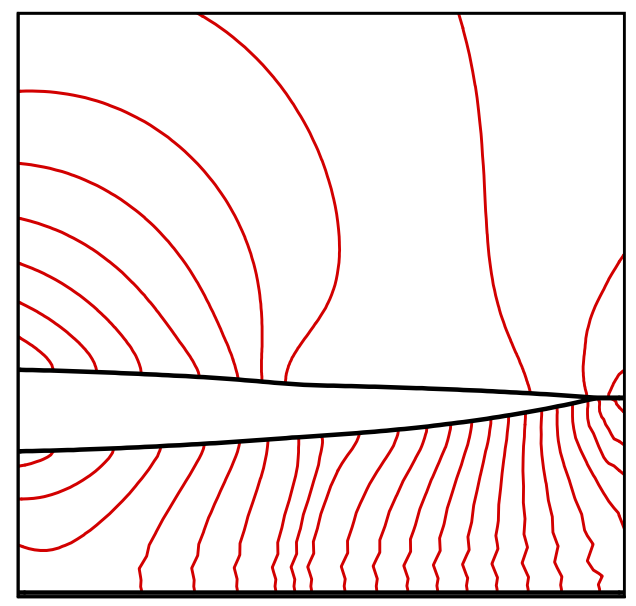

Table 4 Down force, drag coefficient and lift-drag ratio for smart and conventional airfoils for $\mathrm{h} / \mathrm{c}=0.8$

\begin{tabular}{lccccccc}
\hline \multirow{2}{*}{ AOF (deg) } & \multicolumn{3}{c}{ Smart flap } & & \multicolumn{3}{c}{ Convectional flap } \\
\cline { 2 - 5 } \cline { 6 - 8 } & $C L$ & $C D$ & $L / D$ & & $C L$ & $C D$ & $L / D$ \\
\hline+2.5 & -0.160 & 0.0259 & 6.18 & & -0.141 & 0.0268 & 5.26 \\
+5 & -0.337 & 0.0270 & 12.5 & & -0.308 & 0.0276 & 11.2 \\
+7.5 & -0.522 & 0.0278 & 18.8 & & -0.475 & 0.0290 & 16.4 \\
\hline
\end{tabular}

In Figures 26, 27 and 28, the velocity profiles of conventional airfoil have been compared with smart airfoils for conditions $\mathrm{h} / \mathrm{c}=0.5, \mathrm{AOF}=+7.50$. Figure 26 shows velocity profile on the upper surface of airfoil. The figure proves velocity on the smart flap that it is less than conventional flap. Figure 27 illustrates velocity on the low surface of airfoil 
and manifests that velocity in the smart mode is more than conventional airfoils. So, Figure 28 demonstrates the wake profile behind the airfoil. The figure explains that the wake behind the smart flap is faster damp. As the result of this, drag coefficient in the smart flap is less than conventional one.

Figure 26 Comparison smart and conventional flap by velocity profile in upper surface of airfoil at $\mathrm{h} / \mathrm{c}=0.5, \mathrm{AOF}=+7.5^{\circ}$, (a) $\mathrm{x} / \mathrm{c}=0.2$ (b) $\mathrm{x} / \mathrm{c}=0.85$ (see online version for colours)

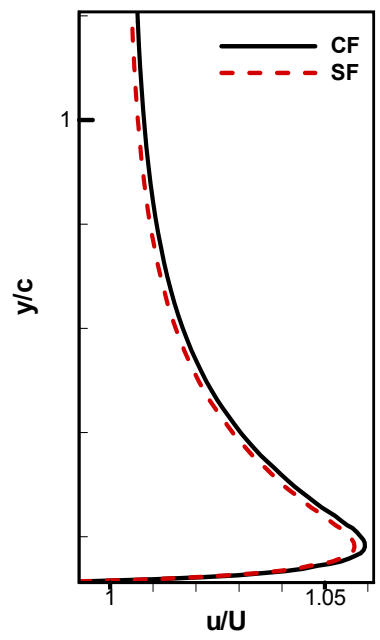

(a)

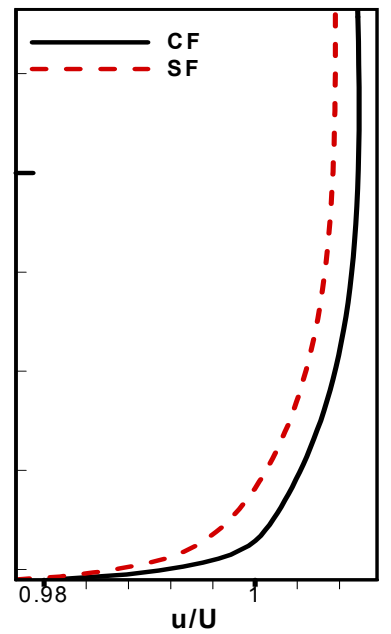

(b)

Figure 27 Comparison smart and conventional flap by velocity profile in lower surface of airfoil at $\mathrm{h} / \mathrm{c}=0.5, \mathrm{AOF}=+7.5^{\circ}$, (a) $\mathrm{x} / \mathrm{c}=0.2(\mathrm{~b}) \mathrm{x} / \mathrm{c}=0.85$ (see online version for colours)

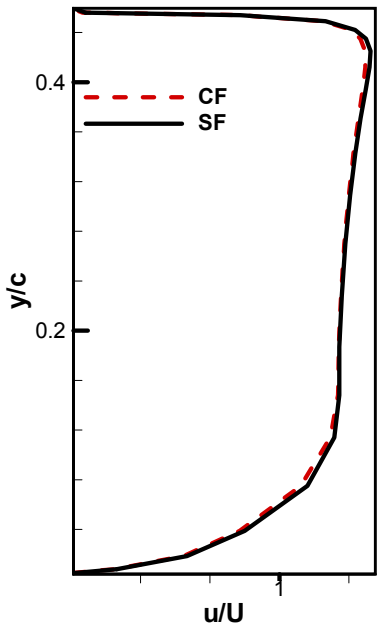

(a)

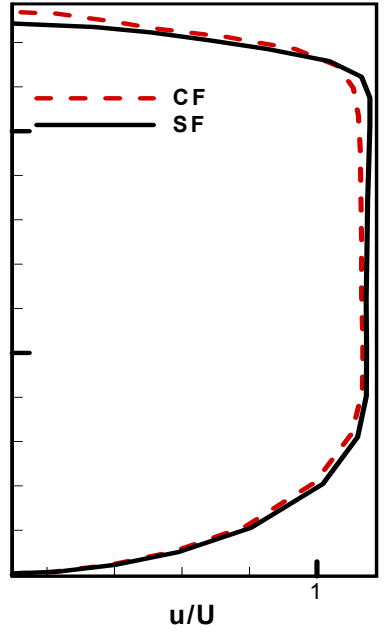

(b) 
Figure 28 Comparison smart and conventional flap by velocity profile in behind the airfoil at $\mathrm{h} / \mathrm{c}=0.5, \mathrm{AOF}=+7.5^{\circ}$, (a) $\mathrm{x} / \mathrm{c}=1.08$ (b) $\mathrm{x} / \mathrm{c}=2$ (see online version for colours)

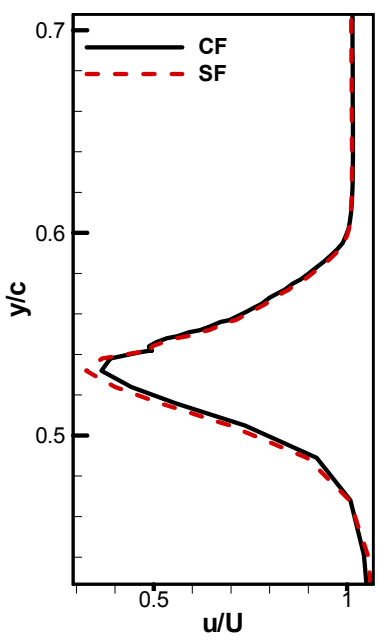

(a)

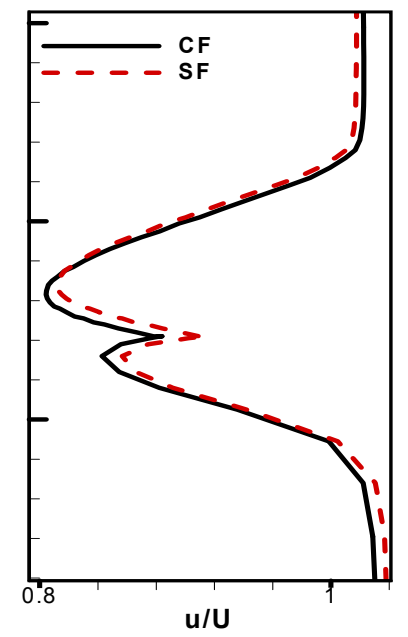

(b)

Table 5 represents that the flow rate passing through the lower surface of airfoil is reduced as the AOF is decreased. In this test, area-section is fixed from the leading edge to the first of flap for the all of flap angle. When the AOF is increased, passing flow rate between the ground surface and lower surface of airfoil is increased. As the results of these, passing flow rate from the upper surface of airfoil is decreased by increasing the AOF and pressure in the pressure side from leading edge to the beginning of flap for $\mathrm{AOF}=+7.5^{\circ}$ is more.

Table 5 Volume flow rate passing between lower surface of airfoil and ground for $\mathrm{h} / \mathrm{c}=0.2$

\begin{tabular}{lcc}
\hline AOF $(\mathrm{deg})$ & Smart flap & Conventional flap \\
\hline$+7.5^{\circ}$ & 0.643 & 0.631 \\
$+5^{\circ}$ & 0.600 & 0.594 \\
$+2.5^{\circ}$ & 0.568 & 0.567 \\
\hline
\end{tabular}

Figure 29 shows the effect of various flap lengths on pressure coefficient distribution on the surface of smart airfoil for $\mathrm{h} / \mathrm{c}=0.5$ and $\mathrm{AOF}=+5^{\circ}$. Three different lengths of $\mathrm{FL} / \mathrm{c}=0.2,0.3,0.4$ are considered. As indicated in this figure, the increase of flap length leads to the increase of pressure coefficient on the upper surface of airfoil and decreasing it in the lower surface of airfoil. In addition, Table 6 confirms the down force and drag coefficients and the $\mathrm{L} / \mathrm{D}$ of these cases. It explains that down force and drag coefficients slightly are increased in longer flap length and L/D ratio is increased, too.

Figure 30 shows velocity profiles on the upper surface of smart airfoil for different flap length for $\mathrm{h} / \mathrm{c}=0.5$ and $\mathrm{AOF}=+5^{\circ}$. These results illustrate that the velocity on the upper surface of airfoil is decreased slightly by increasing flap length. Figure 31 illustrates the velocity profile on the lower surface of airfoil.

Velocity profiles behind the airfoil for different flap lengths have been plotted in Figure 32. It can be found that the wake flow behind the airfoil with longer flap length is stronger and lead to a higher drag coefficient. 
Table 6 Lift and drag coefficients and lift-drag absolute value ratio for smart airfoils for $\mathrm{h} / \mathrm{c}=0.5, \mathrm{AOF}=+5^{\circ}$

\begin{tabular}{lccc}
\hline$F L / c$ & $C L$ & $C D$ & $L / D$ \\
\hline 0.2 & -0.195 & 0.0270 & 7.22 \\
0.3 & -0.290 & 0.0295 & 9.83 \\
0.4 & -0.365 & 0.0310 & 11.8 \\
\hline
\end{tabular}

Figure 29 Pressure coefficient distribution on the surface of the smart airfoil for $\mathrm{h} / \mathrm{c}=0.5$ and $\mathrm{AOF}=+5^{\circ}$ (see online version for colours)

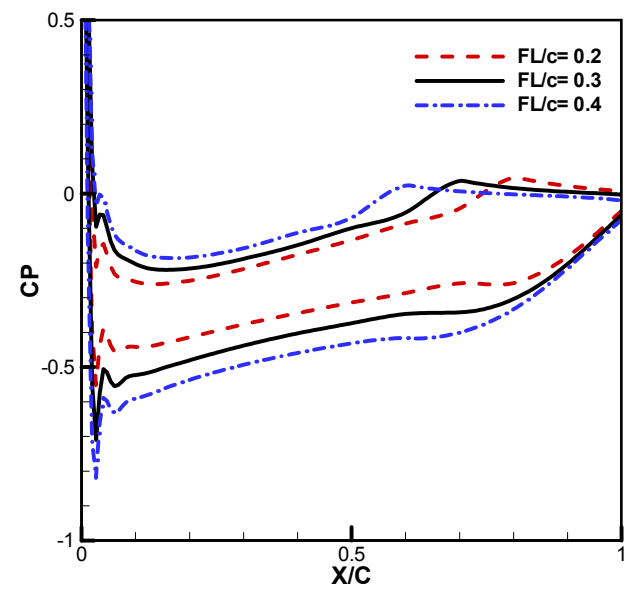

Figure 30 Velocity profile in upper surface of smart airfoil at $\mathrm{h} / \mathrm{c}=0.5, \mathrm{AOF}=+5^{\circ}$, (a) $\mathrm{x} / \mathrm{c}=0.2$ (b) $\mathrm{x} / \mathrm{c}=0.85$ (see online version for colours)

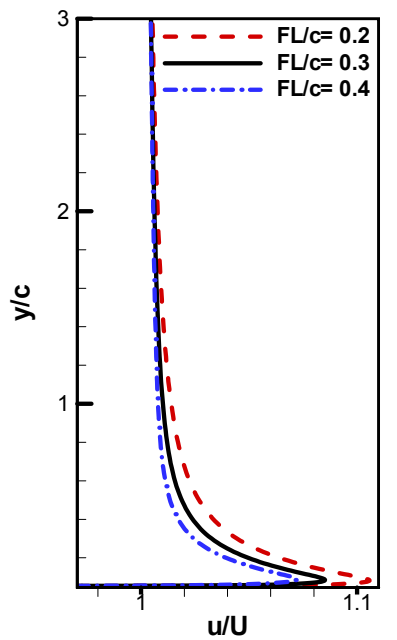

(a)

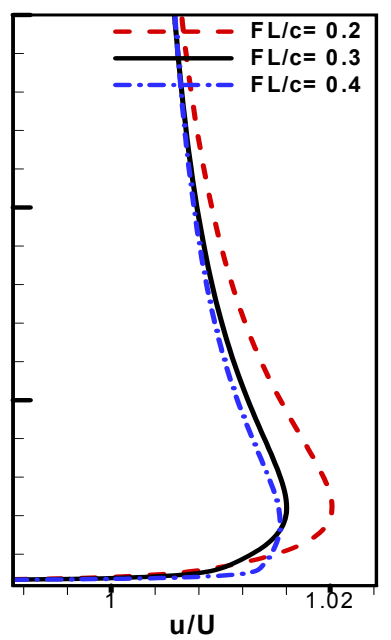

(b) 
Figure 31 Velocity profile in lower surface of smart airfoil at $\mathrm{h} / \mathrm{c}=0.5, \mathrm{AOF}=+5^{\circ}$, (a) $\mathrm{x} / \mathrm{c}=0.2$ (b) $\mathrm{x} / \mathrm{c}=0.85$ (see online version for colours)

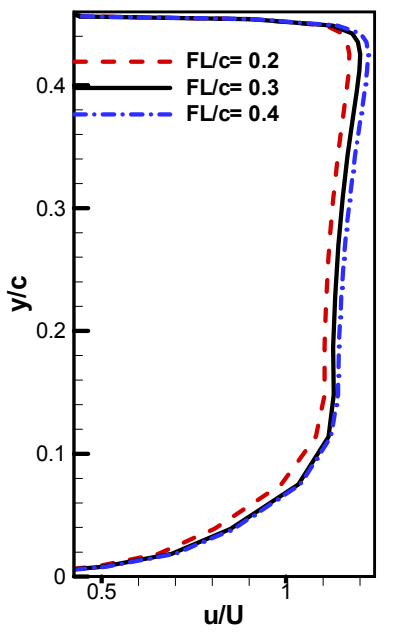

(a)

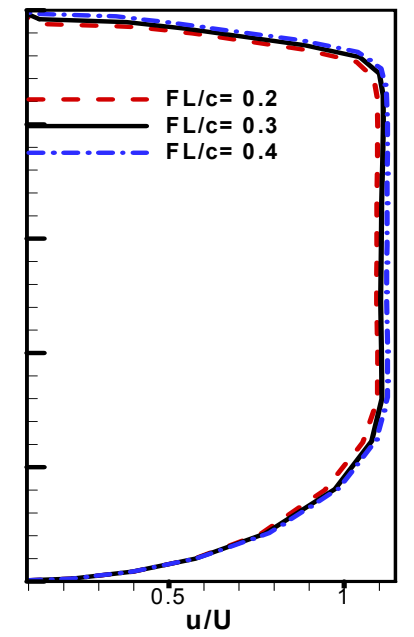

(b)

Figure 32 Velocity profile in behind the smart airfoil at $\mathrm{h} / \mathrm{c}=0.5, \mathrm{AOF}=+5^{\circ}$ (see online version for colours)

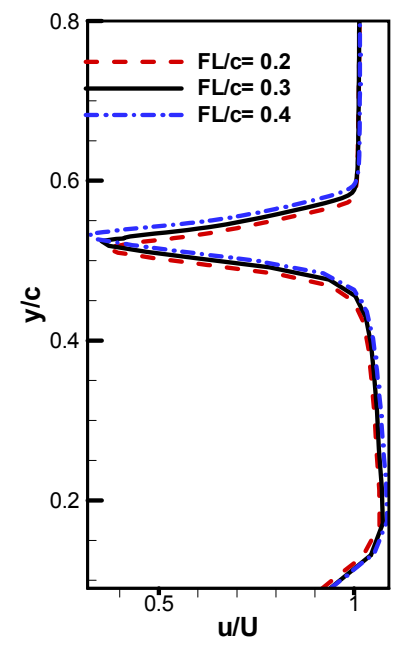

(a)

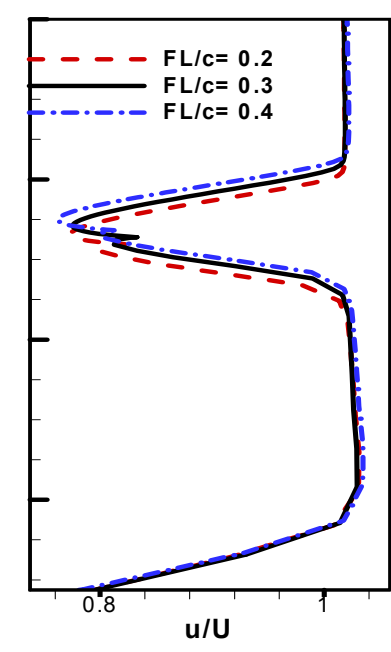

(b)

\section{Conclusions}

Airfoils or wings are used in the front and rear of the car in an effort to generate more down force. The front wing of a race car is an important piece to make safety at high speed. To improve aerodynamic coefficient performance, smart wing can be utilised in these cars, so that in this paper, a smart and conventional flap for race cars are simulated 
and they are compared. For numerical method, a pressure-based implicit procedure is due to solve Navier-Stokes equations. The simulation is applied for different flap length, flap angle and ground clearance. The results confirm that the pressure coefficient distribution in a smart flap is smoother than conventional one and L/D ratio in a smart flap is higher than a conventional one. The highest $\mathrm{L} / \mathrm{D}$ ratio is at $\mathrm{AOF}=+7.5^{\circ}$ and $\mathrm{h} / \mathrm{c}=0.5$. So, the lift and drag coefficients slightly are increased in longer flap length and L/D ratio is increased, too. If smart material is used for race car wings, the performance is higher.

\section{References}

Abdullah, E., et al. (2009) 'Application of smart materials for adaptive airfoil control', Presented at the 47th AIAA Aerospace Sciences Meeting Including the New Horizons Forum and Aerospace Exposition, Orlando, Florida.

Abdullah, E., et al. (2010) 'Numerical simulation of an adaptive airfoil system using SMA actuators', Presented at the 48th AIAA Aerospace Sciences Meeting Including the New Horizons Forum and Aerospace Exposition 2010.

Ahmed, M. and Sharma, S. (2005) 'An investigation on the aerodynamics of a symmetrical airfoil in ground effect', Experimental Thermal and Fluid Science, Vol. 29, pp.633-647.

Ahmed, M., et al. (2003) 'Experimental investigation of the flow field of a symmetrical airfoil in ground effect', in 21st Applied Aerodynamics Conference, Orlando, Florida.

Ahmed, M., et al. (2006) 'Experiments on the aerodynamics of a cambered airfoil in ground effect', in 44th AIAA Aerospace Sciences Meeting and Exhibit, Reno, Nevada.

Anusonti-Inthra, P., et al. (2005) 'Design of a conformable rotor airfoil using distributed piezoelectric actuation', AIAA Journal, Vol. 43, pp.1684-1695.

Barlas, T. and van Kuik, G. (2010) 'Review of state of the art in smart rotor control research for wind turbines', Progress in Aerospace Sciences, Vol. 46, pp.1-27.

Bolonkin, A., et al. (1999) Estimated Benefits of Variable-Geometry Wing Camber Control for Transport Aircraft, Citeseer.

Boschetti, J.P., et al. (2010) 'Stability and performance of a light unmanned airplane in ground effect', in 48th AIAA Aerospace Sciences Meeting Including the New Horizons Forum and Aerospace Exposition, Florida.

Campanile, L. and Anders, S. (2005) 'Aerodynamic and aeroelastic amplification in adaptive belt-rib airfoils', Aerospace Science and Technology, Vol. 9, pp.55-63.

Chinnasamy, P. and Chen, Y. (2005) Application of Computational Fluid Dynamics on Smart Wing Design, University of Nevada, Las Vegas.

Djavareshkian, M. (2001) 'A new NVD scheme in pressure-based finite-volume methods', in 14th Australasian Fluid Mechanics Conference, pp.10-14, Adelaide University, Adelaide, Australia.

Florance, J., et al. (2003) 'Contributions of the NASA Langley Research Center to the DARPA/AFRL/NASA/Northrop Grumman smart wing program', Presented at the 44th AIAA/ASME/ASCE/AHS Structures, Structural Dynamics, and Materials, Conference, Virginia.

Forster, E., et al. (2003) 'Synthesis of a variable geometry trailing edge control surface', AIAA Journal, Vol. 1717.

Goto, K. and Sakurai, H. (2006) 'Numerical study for the optimal flap chord length of a two-element airfoil', SAE International Journal of Passenger Cars-Mechanical Systems, 5 December.

Jasper, M. and Rudell, K. (2006) 'The application of design of experiments to CFD studies of racecar wing configurations', SAE International Journal of Passenger Cars-Mechanical Systems, pp.01-3645. 
Jung, K., et al. (2008) 'Experimental investigation of wing-in-ground effect with a NACA6409 section', Journal of Marine Science and Technology, Vol. 13, pp.317-327.

Katz, J. (2005) 'Aerodynamics of race cars', Annual Review of Fluid Mechanics, Vol. 38, p.27.

Kim, H., et al. (2009) 'Aeronumeric optimal design of a wing-in-ground-effect craft', Journal of Marine Science and Technology, Vol. 14, pp.39-50.

Krajnovi, S. and Davidson, L. (2005) 'Flow around a simplified car, part 1: large Eddy simulation', Journal of Fluids Engineering, Vol. 127, p.907.

Kudva, J., et al. (1997) 'Design, fabrication, and testing of the DARPA/Wright Lab' smart wing wind tunnel model', Journal of American Institute of Aeronautics and Astronautics (AIAA).

Lee, J., et al. (2010) 'Optimization of wings in ground effect using multi-objective genetic algorithm', in 48th AIAA Aerospace Sciences Meeting Including the New Horizons Forum and Aerospace Exposition, Florida.

Majji, M., et al. (2007) 'Design of a Morphing wing: modeling and experiments', Presented at the AIAA Atmospheric Flight Mechanics Conference and Exhibit, South Carolina.

Matsuzaki, Y. and Torii, H. (2006) 'Flutter boundary prediction of an adaptive smart wing during process of adaptation using steady-state response data', Presented at the 47th AIAA/ASME/ASCE/AHS Structures, Structural Dynamics, and Materials Conference, Rhode Island.

Mokhtar, W. (2005) 'A numerical study of high-lift single element airfoils with ground effect for racing cars', SAE Transactions, Vol. 114, pp.682-688.

Mokhtar, W. (2008) 'Aerodynamics of high-lift wings with ground effect for racecars', Presented at the SAE World Congress.

Mokhtar, W. and Lane, J. (2009) 'Racecar front wing aerodynamics', SAE International Journal of Passenger Cars-Mechanical Systems, Vol. 1, p.1392.

Moon, Y., et al. (2005) 'Aerodynamic investigation of three-dimensional wings in ground effect for aero-levitation electric vehicle', Aerospace Science and Technology, Vol. 9, pp.485-494.

Park, K. and Lee, J. (2008) 'Influence of endplate on aerodynamic characteristics of low-aspect-ratio wing in ground effect', Journal of Mechanical Science and Technology, Vol. 22, pp.2578-2589.

Park, K., et al. (2009) 'Aerodynamics and optimization of airfoil under ground effect', International Journal of Mechanical Systems Science and Engineering, Vol. 1.

Pern, N.J. and Jacob, J.D. (1999) 'Wake vortex mitigation using adaptive airfoils', Presented at the 37th AIAA. Aerospace Sciences Meeting and Exhibit.

Quackenbush, T., et al. (2005) 'Design and testing of a variable geometry ducted propulsor using shape memory alloy actuation', in 43rd AIAA Aerospace sciences Meeting and Exhibit, Reno, Nevada.

Reddy, J. and Gupta, M. (2006) 'Finding the optimum angle of attack for the front wing of an F1 car using CFD', in Proceedings of the 4th WSEAS International Conference on Fluid Mechanics and Aerodynamics, Elounda, Greece, pp.29-34.

Smith, J. (2007) 'Computational analysis of airfoils in ground effect for use as a design tool', MSc thesis, Mechanical and Aerospace Engineering Department, Morgantown, West Virginia University, West Virginia.

Smith, J., et al. (2008) 'The validation of an airfoil in the ground effect regime using 2-D CFD analysis', Presented at the 26th AIAA Aerodynamic Measurement Technology and Ground Testing Conference, Seattle, Washington.

Takahisa, M., et al. (2006) 'Study of unsteady characteristics of wings in ground effect', in Third International Symposium on Transdisciplinary Fluid Integration, Matsushima, Miyagi, Japan.

Tiseo, B. and Koopmann, G. (2006) 'Smart tunable dynamic vibration absorbers', in 12th AIAA/CEAS Aeroacoustics Conference (27th AIAA Aeroacoustics Conference), Cambridge, Massachusetts. 
Ueno, D., et al. (2006) 'CFD analysis in research and development of racing car', SAE International Journal of Passenger Cars-Mechanical Systems, 5 December.

$\mathrm{Vu}, \mathrm{P}$. (2006) 'CFD study of wing tip vortices for inverted airfoils in ground effect', MS thesis, School of Engineering, Cranfield University.

Wickramasinghe, V., et al. (2009) 'Design and verification of a smart wing for an extremely-agile micro-air-vehicle', Presented at the 50th AIAA/ASME/ASCE/AHS/ASC Structural Dynamics, and Materials Conference, California.

Ying-chao, Z. and Li-min, F. (2006) 'Transient aerodynamic numerical simulation of simplified shape cars under condition of opposite meet side-by-side in tunnel [J]', Journal of Jilin University, Engineering and Technology ed., Vol. 3.

Zerihan, J. and Zhang, Z. (2000) 'Aerodynamics of a single element wing in ground effect', Journal of Aircraft, Vol. 37, pp.1058-1064.

Zerihan, J. and Zhang, X. (2001) 'Aerodynamics of Gurney flaps on a wing in ground effect', AIAA Journal, Vol. 39, pp.772-780.

\section{Nomenclature}

\begin{tabular}{llll}
\hline CF & Conventional airfoil & T & Time \\
SF & Smart airfoil & $\tilde{\phi}$ & Normalised scalar quantity \\
C & Cord length & K & A factor in SBIC scheme to determine a special scheme \\
L & Lift force & $\omega_{0}$ & Weight/unit length $(\mathrm{N} / \mathrm{m})$ \\
D & Drag force & $\bar{I}$ & Area moment of inertia $\left(\mathrm{m}^{4}\right)$ \\
CL & Lift coefficient & B & Length of the beam \\
CD & Drag coefficient & X & Horizontal Cartesian coordinate \\
F1 & Formula one race & Y & Vertical Cartesian coordinate \\
WIG & Wing in ground effect & E & Young's modulus \\
SMA & Shape memory alloy & $\rho$ & Density \\
H & Ground clearances & P & Pressure \\
AOF & Angle of flap & $\Gamma$ & Diffusivity coefficient \\
AOA & Angle of attack & $\overrightarrow{\mathbf{q}}$ & Scalar flux vector \\
A & Cell face area & F & Mass flux \\
Re & Reynolds number & $\overrightarrow{\mathbf{T}}$ & Stress tensor \\
$\mu$ & Dynamic viscosity & $\delta v$ & Cell volume \\
$\vec{S}$ & Source term & $\overrightarrow{\mathbf{V}}$ & Velocity vector \\
$\phi$ & Scalar quantity & I & Flux \\
\hline
\end{tabular}

